\section{Another Twist on the Dormia Basket}

S. S. Mudan, R. S. Taylor, M. J. Knight

Department of Hepatobiliary Surgery.

St. George's Hospital, London, UK

Corresponding Author

\section{S. S. Mudan}

Department of Hepatobiliary Surgery

3rd Floor, St. James's Wing

St. George's Hospital

Blackshaw Road

London SW17 OQT

UK

Fax: + 44-1816728114

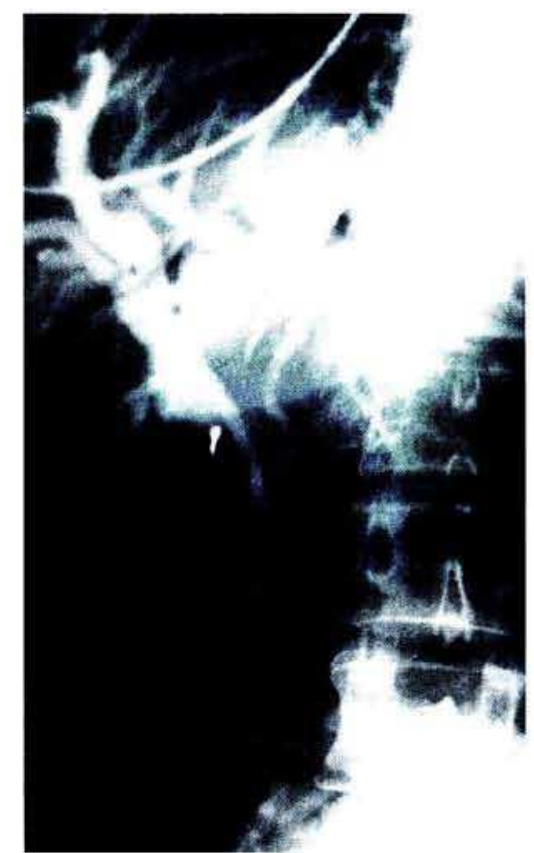

Figure 1: Retrieval of a $2 \mathrm{~cm}$ common bile duct stone was attempted using a Dormia basket and crushing oversleeve. After some turns on the crusher the entire wire basekt snapped off within the bile duct, still engaged around the calculus.

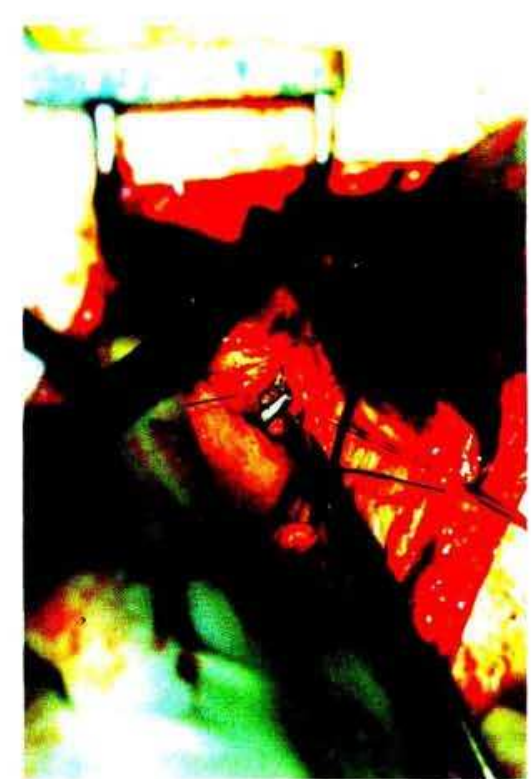

Figure 2: The retrieval procedure was abandoned and a 10 FG stent was placed in the bile duct alongside the stone. The same day an open cholecystectomy and bile duct exploration was performed and the stone, still embraced by the detached wire basket, together with the stent, was removed. 